\title{
The utility of urine sulphosalicylic acid testing in the detection of non-albumin proteinuria
}

\author{
S Ndamase, MB ChB; R Freercks, MB ChB, FCP (SA), Cert Nephrology (SA), MPhil \\ Division of Nephrology and Hypertension, Department of Medicine, Faculty of Health Sciences, University of Cape Town, and Renal Unit, \\ Livingstone Hospital, Port Elizabeth, South Africa
}

Corresponding author: R Freercks (robert.freercks@uct.ac.za)

\begin{abstract}
We report two cases of immunoglobulin light chain proteinuria (Bence Jones proteinuria) detected by simple side-room investigations: urine dipstick negative/1+, but with strong positive precipitation on addition of an equal volume of sulphosalicylic acid (SSA) $3 \%$. We highlight a significant limitation of urine dipstick testing, namely specificity for albumin, and the utility of SSA testing for the detection of urinary free light chain immunoglobulins.
\end{abstract}

S Afr Med J 2015;105(2):XXX. DOI:10.7196/SAMJ.9270

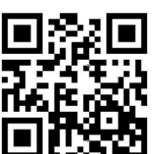

\section{Case 1}

A 51-year-old woman with hypertension and type 2 diabetes mellitus was referred for evaluation of her chronic kidney disease. Her creatinine was $124 \mu \mathrm{mol} / \mathrm{L}$, urea $5.6 \mathrm{mmol} / \mathrm{L}$ and estimated glomerular filtration rate $40 \mathrm{~mL} / \mathrm{min}$. She had a severe normocytic anaemia, with a haemoglobin of $6.5 \mathrm{~g} / \mathrm{dL}$. On further enquiry she gave a history of unintentional weight loss of $9 \mathrm{~kg}$. She was pale, with no lymphadenopathy or oedema. Urine dipstick was negative for proteinuria, but the urine protein:creatinine ratio was $0.8 \mathrm{~g} / \mathrm{mmol}$ (normal range $<0.02 \mathrm{~g} / \mathrm{mmol}$ ), indicating nephrotic range proteinuria. The addition of sulphosalicylic acid (SSA) to her urine caused immediate turbidity (Fig. 1). A diagnosis of multiple myeloma was

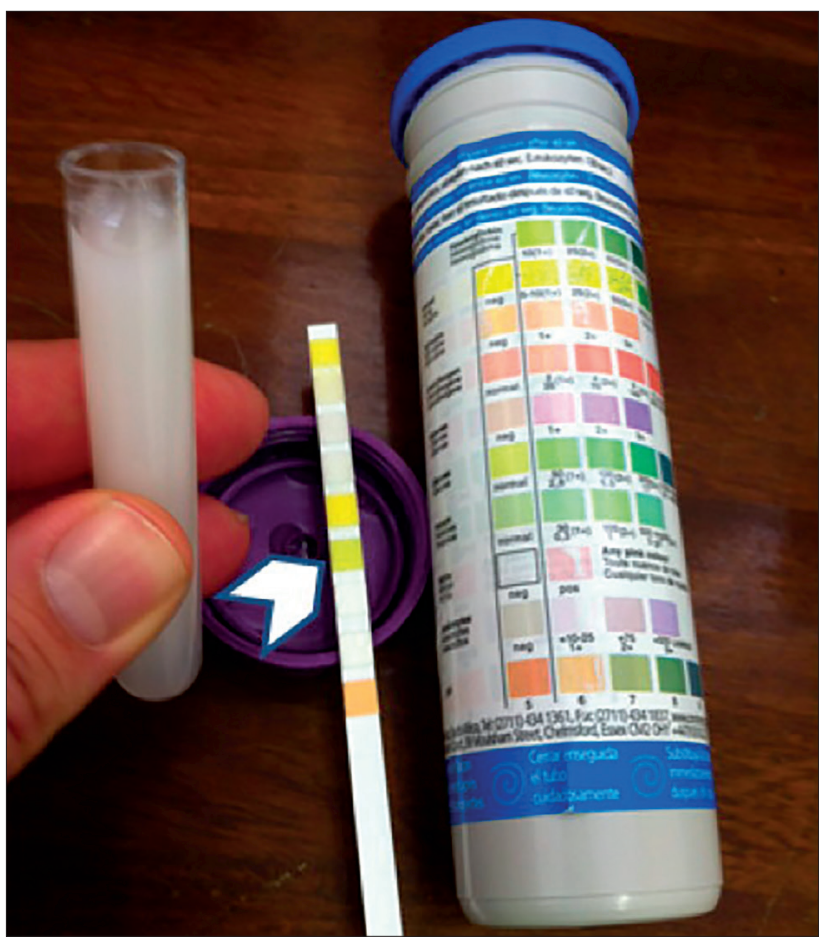

Fig. 1. Case 1. Turbidity with the urine sulphosalicylic acid 3\% precipitation test. Negative dipstick test for proteinuria (white arrow-head). therefore suspected and serum and urine electrophoresis confirmed a monoclonal lambda peak. Serum free kappa light chains were $12.9 \mathrm{mg} / \mathrm{L}$ (3.3 - 19.4), and free lambda light chains $5688 \mathrm{mg} / \mathrm{L}$ (5.7 - 26.3).

\section{Case 2}

A 54-year-old man presented with a 2-day history of headache and epistaxis. He was pale, with no lymphadenopathy and an otherwise normal physical examination. Initial testing revealed a severe bicytopenia: haemoglobin $6.2 \mathrm{~g} / \mathrm{dL}$, mean corpuscular volume $85.8 \mathrm{fL}$, and platelets $10 \times 10^{9} / \mathrm{L}$. A peripheral smear showed occasional teardrop cells with a leuco-erythroblastic reaction and no fragments or platelet clumping. His urea was $14.9 \mathrm{mmol} / \mathrm{L}$ and creatinine $460 \mu \mathrm{mol} / \mathrm{L}$. Urinary dipstick testing showed only $1+$ proteinuria, while the urine protein:creatinine ratio was markedly elevated at $1.3 \mathrm{~g} / \mathrm{mmol}$. On addition of SSA, dense turbidity was immediately noted. A diagnosis of multiple myeloma was subsequently confirmed on bone marrow biopsy. Serum free kappa light chains were $8.2 \mathrm{mg} / \mathrm{L}$ (3.3 - 19.4) and lambda light chains $27098.0 \mathrm{mg} / \mathrm{L}(5.5$ - 26.3).

\section{Discussion}

The urine dipstick is specific for albumin and will miss positively charged proteins in the urine, such as immunoglobulin light chains. ${ }^{[1]}$ The bedside detection of non-albumin proteinuria is aided by the use of a simple, inexpensive and often-overlooked investigation: addition of SSA 3\% to urine. The degree of turbidity provides a semiquantitative method for proteinuria detection. ${ }^{[2]}$ Discordance between SSA and dipstick testing (where SSA is strongly positive and dipstick negative or low positive) mainly suggests the presence of non-albumin proteinuria, usually immunoglobulin light chain excretion. ${ }^{[3]}$ This reminder may be of particular interest to clinicians in the South African public sector, where serum and urine electrophoresis results can take 3 - 4 weeks to become available. However, SSA should not substitute urine electrophoresis, as small quantities of monoclonal free light chains may be missed. ${ }^{[4]}$

\section{References}

1. Kashif W, Siddiqi N, Dincer HE, et al. Proteinuria: How to evaluate an important finding. Cleve Clin Med 2003;70(6):535-547. [http://dx.doi.org/10.3949/ccjm.70.6.535]

Arnulfo J, Penagos V, Jairo J, et al. Use of sulfosalicylic acid in the detection of proteinuria and its application to hypertensive problems in pregnancy. Iatreia 2011;24(3):259-266.

. Gyure W. Comparison of several methods for semiquantitative determination of urinary protein. Clin Chem 1977;23(5):876-879

4. Said A, Naderi A, Reilly RF Primary care approach to proteinuria. I Am Board Fam Med 2008;21(6):569-574. [http://dx.doi.org/10.3122/jabfm.2008.06.070080] 